Research Paper

\title{
Efficacy and Safety of Nivolumab in Patients with Advanced Non-small-cell Lung Cancer and Poor Performance Status
}

\author{
Hideyuki Katsura ${ }^{1}$, Yukio Suga ${ }^{2}$, Tomoyuki Araya ${ }^{3}{ }^{凶}$, Toshiyuki Kita ${ }^{3}$, Taro Yoneda ${ }^{4}$, Nobuyoshi Tanaka ${ }^{5}$, \\ Ayumi Kawabata ${ }^{1}$, Sotoki Ishita ${ }^{1}$, Hiroki Mase ${ }^{6}$ \\ 1. Department of Pharmacy, Komatsu Municipal Hospital \\ 2. Department of Clinical Drug Informatics, Faculty of Pharmacy, Institute of Medical, Pharmaceutical \& Health Science, Kanazawa University \\ 3. Department of Respiratory Medicine, National Hospital Organization Kanazawa Medical Center \\ 4. Department of Respiratory Medicine, Komatsu Municipal Hospital \\ 5. Department of Surgery, Komatsu Municipal Hospital \\ 6. Department of Pharmacy, National Hospital Organization Kanazawa Medical Center \\ $\triangle$ Corresponding author: Tomoyuki Araya, Department of Respiratory Medicine, National Hospital Organization Kanazawa Medical Center, \\ Shimoishibiki-machi 1-1, Kanazawa 920-8650, Japan. Tel: +81-76-262-4161; Fax: +81-76-222-2758; E-mail: komatsu_alone@yahoo.co.jp \\ (c) Ivyspring International Publisher. This is an open access article distributed under the terms of the Creative Commons Attribution (CC BY-NC) license \\ (https:// creativecommons.org/licenses/by-nc/4.0/). See http://ivyspring.com/terms for full terms and conditions.
}

Received: 2018.11.04; Accepted: 2019.03.31; Published: 2019.05.19

\begin{abstract}
Background: Nivolumab efficacy in patients with non-small-cell lung cancer (NSCLC) and performance status (PS) of 2-4 is unclear. We aimed to compare survival, treatment efficacy, and safety in patients with NSCLC with poor PS who received nivolumab plus best supportive care (BSC) with those in patients who received $\mathrm{BSC}$ alone in a palliative care unit (PCU).

Patients and methods: This retrospective study included 99 consecutive patients with NSCLC who received nivolumab plus BSC or BSC alone between December 2015 and March 2018.

Results: In total, 43 patients with PS of 0-1 (good PS group) and 20 patients with PS of 2-4 (poor PS group) received nivolumab plus BSC; the remaining 36 patients received BSC alone in the PCU (PC group). Median overall survival was 32 days [95\% confidence interval $(\mathrm{Cl}), 21-43]$ in the poor PS group and 31 days $(95 \% \mathrm{Cl}, 25-37)$ in the $\mathrm{PC}$ group (hazard ratio, $0.653 ; 95 \% \mathrm{Cl}, 0.368-1.158 ; \mathrm{P}=0.137$ ). Moreover, median overall survival in patients with PS of 3 or 4 among the poor PS group was not significantly longer than that in the PC group $(\mathrm{HR}, 1.235 ; 95 \% \mathrm{Cl}, 0.646-2.360 ; \mathrm{P}=0.516)$. The frequency of severe pneumonitis in the poor PS group was significantly higher than that in the good PS group $(25 \%$ vs. $2 \%, P=0.010)$.

Conclusion: Survival benefit of nivolumab in patients with NSCLC with poor PS, especially 3 or 4, was not confirmed. Further studies with larger numbers of patients are required to confirm our results.
\end{abstract}

Key words: Clinical practice; Immune checkpoint inhibitor; Best supportive care; Overall survival; Pneumonitis

\section{Introduction}

Non-small-cell lung cancer (NSCLC) is still the leading cause of cancer-related deaths worldwide [1]. The advent of cancer immunotherapy represents the most important innovation in the treatment of NSCLC over the last few decades. Two phase III studies have demonstrated the favorable safety profile of Nivolumab [a fully human programmed cell death protein 1 (PD-1) immune checkpoint inhibitor antibody] and its superiority over docetaxel [a standard second line treatment for patients with advanced NSCLC with Eastern Cooperative Oncology Group Performance Status (PS) of 0 or 1] with respect to overall survival $[2,3]$. Moreover, the estimated 3 -year overall survival rate of patients with NSCLC treated with nivolumab was recently reported to be $17 \%$ [4]. However, much of the available evidence of the benefits of nivolumab emanates from studies on patients with PS of 0 or 1 . Although PS of 2-4 was 
shown to be associated with early progression in patients with NSCLC receiving nivolumab [5-12], the survival benefit of nivolumab in patients with PS of 2 remains controversial; in a phase II trial (CheckMate 171) the efficacy and tolerability in patients with PS of 2 was comparable to that in the overall population [13]. In addition, patients with PS of 3 or 4 are considered unfit for anticancer drugs and were recommended to receive best supportive care (BSC) [14]. Therefore, it is possible that among patients with PS of 2-4, the benefit of nivolumab in patients with PS of 3 or 4 may be different from that in patients with PS of 2. However, the survival benefit of nivolumab plus BSC compared with BSC alone in patients with PS of 3 or 4 is not well characterized. In this study, we retrospectively investigated the efficacy and safety of nivolumab therapy in patients with NSCLC having poor PS, especially 3 or 4 , and assessed the survival outcomes. The objective was to evaluate the benefit of nivolumab treatment in these patients.

\section{Patients and methods}

\section{Search strategy}

Medical records of patients were retrospectively reviewed. We collected data pertaining to consecutive patients with advanced or recurrent NSCLC who received nivolumab as first immunotherapy or were admitted to the palliative care unit (PCU) between December 2015 and March 2018 at the Komatsu Municipal Hospital and the National Hospital Organization Kanazawa Medical Center. The typical reason for admission to our PCU was deterioration of performance status owing to disease progression, adverse events of chemotherapy, and worsening of comorbidities. Patients who received at least one dose of nivolumab ( $3 \mathrm{mg} / \mathrm{kg}$ intravenously every 2 weeks) plus BSC and patients who received BSC alone in the PCU were eligible for this study. The patients in the PCU who were previously treated with nivolumab or had PS of 0-2 were excluded from the analysis. This study was approved by the institutional review boards of the Komatsu Municipal Hospital (29-26) and the National Hospital Organization Kanazawa Medical Center (H30-003).

\section{Data Collection}

Data pertaining to the following variables were collected: age, gender, smoking history, PS, histologic type, epidermal growth factor receptor mutation status, anaplastic lymphoma kinase fusion genes, the number of prior treatment regimens, overall survival, progression-free survival, response rate, and nivolumab-related adverse events. Survival of patients who received nivolumab was calculated as the time from initiation of this drug to death from any cause or last follow-up (May 22, 2018). Similarly, the survival of patients who received BSC alone was calculated as the time from admission to the PCU to death from any cause or last follow-up. Progression-free survival was defined as the time from initiation of nivolumab to objective evidence of tumor progression [as determined by the Response Evaluation Criteria in Solid Tumors (RECIST) version 1.1], death from any cause or last follow-up, whichever occurred first. The response to nivolumab was assessed using RECIST version 1.1. The safety profile was assessed and graded using the Common Terminology Criteria for Adverse Events, version 4.03.

\section{Statistical analysis}

Between-group differences with respect to baseline characteristics were assessed using unpaired $t$-test, Fisher's exact test, Chi-squared test, and Mann-Whitney U-test for categorical variables. Overall survival and progression-free survival were assessed by Kaplan-Meier method, and between-group differences assessed using the log-rank test. Hazard ratios (HR) and confidence intervals (CI) were estimated using a Cox proportional-hazards model. Adverse events and the response to nivolumab were assessed by Fisher's exact test and Chi-squared test. All statistical analyses were performed using the SPSS version 24.0 (IBM Corp., Armonk, NY, USA). P values less than 0.05 were considered statistically significant.

\section{Results}

\section{Patients and treatment}

A total of 99 consecutive patients were enrolled in this study. Of these, 63 patients were treated with nivolumab: $68 \%$ (43/63) patients had a PS score of $0-1$ (good PS group) and 32\% (20/63) patients had a PS score of 2 to 4 (poor PS group). Out of 46 patients who were admitted to the PCU during the study reference period, 36 patients were enrolled (PC group). Eight patients with a history of nivolumab treatment and 2 patients who had PS of 2 were excluded from the analysis. Patient characteristics are shown in Table 1. The median age of patients in the poor PS group was 69 years (range, $55-84$ years). Further, $80 \%(16 / 20)$ of these patients were men, and $50 \%(10 / 20)$ were receiving nivolumab as the second-line treatment. The proportion of female, never smoked, PS of 3 or 4, adenocarcinoma and positive EGFR mutation status in the poor PS group were significantly lower than that in the PC group $(20 \%$ vs. $50 \%, \mathrm{P}=0.028,5 \%$ vs. $50 \%, \mathrm{P}=0.001,65 \%$ vs. $100 \% \mathrm{P}<0.001,45 \%$ vs. $81 \% \mathrm{P}$ $=0.010$, and $10 \%$ vs. $36 \% \mathrm{P}=0.008$, respectively). The proportion of current or former smokers and patients 
with PS of 3 among the PS 3 or 4 group were significantly higher than that in the PC group $(92 \%$ vs. $50 \%, \mathrm{P}=0.007$ and $92 \%$ vs. $56 \% \mathrm{P}=0.018$, respectively). There was little data available on tumor programmed death-ligand 1 (PD-L1) expression because routine tumor immunostaining for PD-L1 was not performed. Nivolumab was administered at a standard dose of $3 \mathrm{mg} / \mathrm{kg}$ every 2 weeks. The median treatment cycle of nivolumab was 1 in the poor PS group and 8 in the good PS group $(P<0.001)$.

\section{Efficacy}

The median follow-up was 90 days (range: 2-789 days). At the time of last follow-up, 79 patients $(80 \%)$ had died [19 (95\%) in the poor PS group, 24 (56\%) in the good PS group, and $36(100 \%)$ in the PC group]. The median overall survival was 32 days $(95 \% \mathrm{CI}$, $21-43)$ in the poor PS group, 412 days $(95 \% \mathrm{CI}$, $236-588)$ in the good PS group, and 31 days $(95 \% \mathrm{CI}$, 25-37) in the PC group (Fig. 1A). Overall survival in the poor PS group was not significantly longer than that in the PC group (HR, 0.653; 95\% CI, 0.368-1.158; P $=0.137)$, although that in the good PS group was significantly longer than that in the PC group (HR, 0.061; 95\% CI, 0.028-0.131; P < 0.001) (Fig. 1A). The median overall survival was significantly longer in patients with PS of 2 among the poor PS group than that in patients with PS of 3 or 4 among the poor PS group or that in the PC group (95 days vs. 28 days, HR, 0.266; 95\% CI, 0.085-0839; $\mathrm{P}=0.014$, and 95 days vs. 31 days, $\mathrm{HR}, 0.283 ; 95 \% \mathrm{CI}, 0.109-0.739 ; \mathrm{P}=0.006$, respectively) (Fig 1B). Moreover, median overall survival in patients with PS of 3 or 4 among the poor PS group was not significantly longer than that in the PC group (HR, 1.235; 95\% CI, 0.646-2.360; P = 0.516) (Fig. 1B). The median progression-free survival in the poor PS group was 28 days $(95 \% \mathrm{CI}, 6-44)$ as compared to 110 days (95\% CI, 32-188) in the good PS group (HR, 4.050; 95\% CI, 2.217-7.400; $\mathrm{P}<0.001$ ) (Fig. $2 \mathrm{~A})$. The median progression-free survival was significantly longer in patients with PS of 2 among the poor PS group than that in patients with PS of 3 or 4 among the poor PS group (65 days vs. 14 days, HR, 0.055; 95\% CI, 0.007-0447; P < 0.001) (Fig 2B). The rates of confirmed objective response and disease control were $0 \%(95 \% \mathrm{CI}, 0-23)$ and $15 \%(95 \% \mathrm{CI}, 0-31)(\mathrm{P}<$ 0.001 ) in the poor PS group, and $23 \%$ (95\% CI, 11-36) and $72 \%(95 \% \mathrm{CI}, 59-85)(\mathrm{P}<0.001)$ in the good PS group (Table 2).

Table 1. Patient Characteristics $(n=99)$.

\begin{tabular}{|c|c|c|c|c|c|c|c|c|c|}
\hline \multirow[t]{2}{*}{ Characteristics } & \multicolumn{3}{|c|}{ PS 2-4 (N = 20) } & \multirow{2}{*}{$\begin{array}{l}\text { PS } 0 / 1(N= \\
43)\end{array}$} & \multirow{2}{*}{$\begin{array}{l}P C(N= \\
36)\end{array}$} & \multirow{2}{*}{$\begin{array}{l}\text { PS } 2-4 \text { vs. PS } \\
0 / 1 \\
p \text { value }\end{array}$} & \multirow{2}{*}{$\begin{array}{l}\text { PS 2-4 vs. } \\
\text { PC } \\
p \text { value }\end{array}$} & \multirow{2}{*}{$\begin{array}{l}\text { PS } 3 / 4 \text { vs. } \\
\text { PS } 2 \\
p \text { value }\end{array}$} & \multirow{2}{*}{$\begin{array}{l}\text { PS } 3 / 4 \text { vs. } \\
\text { PC } \\
p p \text { value }\end{array}$} \\
\hline & PS $2(\mathrm{~N}=7)$ & $\mathrm{PS} 3 / 4(\mathrm{~N}=13)$ & Total $(\mathrm{N}=20)$ & & & & & & \\
\hline \multicolumn{10}{|l|}{ Age (years) } \\
\hline Median & 69 & 68 & 69 & 70 & 74 & 0.882 & 0.171 & 0.215 & 0.100 \\
\hline Range & $64-84$ & $55-80$ & $55-84$ & $48-90$ & $44-91$ & & & & \\
\hline \multicolumn{10}{|l|}{ Gender [n (\%)] } \\
\hline Male & $6(86)$ & $10(77)$ & $16(80)$ & $36(84)$ & $18(50)$ & 0.732 & 0.028 & 1.000 & 0.093 \\
\hline Female & $1(14)$ & $3(23)$ & $4(20)$ & $7(16)$ & $18(50)$ & & & & \\
\hline \multicolumn{10}{|l|}{ Smoking status [n (\%)] } \\
\hline Current or former smoker & $7(100)$ & $12(92)$ & $19(95)$ & $39(91)$ & $18(50)$ & 1.000 & 0.001 & 1.000 & 0.007 \\
\hline Never smoked & 0 & $1(8)$ & $1(5)$ & $4(9)$ & $18(50)$ & & & & \\
\hline \multicolumn{10}{|l|}{ PS [n (\%)] } \\
\hline 0 & 0 & 0 & 0 & $22(51)$ & 0 & & & & \\
\hline 1 & 0 & 0 & 0 & $21(49)$ & 0 & & & & \\
\hline 2 & $7(100)$ & 0 & $7(35)$ & 0 & 0 & & & & \\
\hline 3 & 0 & $12(92)$ & $12(60)$ & 0 & $20(56)$ & $<0.001$ & $<0.001$ & $<0.001$ & 0.018 \\
\hline 4 & 0 & $1(8)$ & $1(5)$ & 0 & $16(44)$ & & & & \\
\hline \multicolumn{10}{|l|}{ Histology [n (\%)] } \\
\hline Adenocarcinoma & $3(43)$ & $6(47)$ & $9(45)$ & $23(53)$ & $29(81)$ & 0.796 & 0.010 & 0.050 & 0.382 \\
\hline Squamous & $4(57)$ & $5(38)$ & $9(45)$ & $18(42)$ & $5(14)$ & & & & \\
\hline Others & 0 & $2(15)$ & $2(10)$ & $2(5)$ & $2(6)$ & & & & \\
\hline Positive EGFR mutation status [n (\%)] & 0 & $2(15)$ & $2(10)$ & $4(9)$ & $13(36)$ & 0.588 & 0.008 & 1.000 & 0.069 \\
\hline Positive ALK translocation status [n (\%)] & 0 & 0 & 0 & 0 & $1(3)$ & 1.000 & 1.000 & 1.000 & 1.000 \\
\hline No driver or unknown $[\mathrm{n}(\%)]$ & $7(100)$ & $11(85)$ & $18(90)$ & $39(91)$ & $22(61)$ & & & & \\
\hline Number of prior regimens $[\mathrm{n}(\%)]$ & & & & & & 0.937 & - & 0.115 & - \\
\hline 1 & $5(71)$ & $5(38)$ & $10(50)$ & $21(49)$ & & & & & \\
\hline 2 & $2(29)$ & $3(23)$ & $5(25)$ & $11(25)$ & & & & & \\
\hline 3 & 0 & $2(15)$ & $2(10)$ & $6(14)$ & & & & & \\
\hline$>3$ & 0 & $3(24)$ & $3(15)$ & $5(12)$ & & & & & \\
\hline \multicolumn{10}{|l|}{ Number of treatment cycles [n (\%)] } \\
\hline Median & 2 & 1 & 1 & 8 & & $<0.001$ & & & \\
\hline Range & $1-6$ & $1-5$ & $1-6$ & $1-56$ & & & & & \\
\hline $\begin{array}{l}\text { History of thoracic radiotherapy within one year } \\
{[\mathrm{n}(\%)]}\end{array}$ & $1(14)$ & $5(38)$ & $6(30)$ & $4(9)$ & $2(6)$ & 0.054 & & 0.354 & \\
\hline
\end{tabular}

Abbreviations: PS: performance status; PC: palliative care; EGFR: epidermal growth factor receptor; ALK: anaplastic lymphoma kinase. 
A.

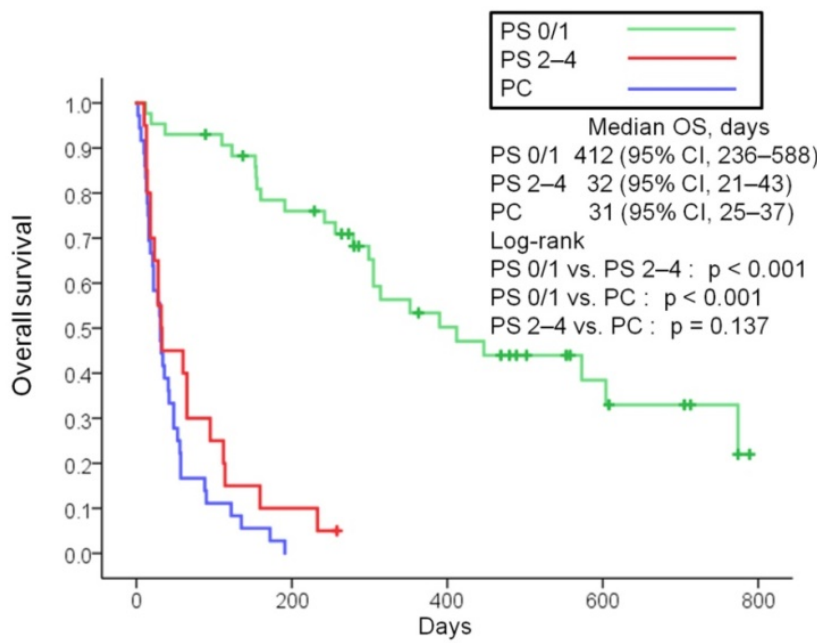

B.

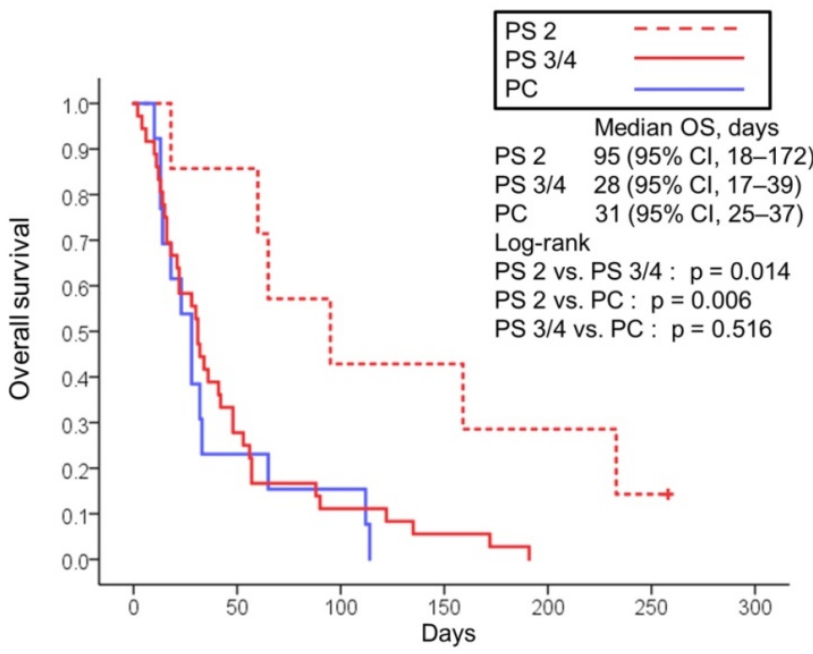

Figure 1. Kaplan-Meier curves for overall survival of patients with PS of $0 / 1$ or 2 to 4 treated with nivolumab and overall survival of patients in palliative care (A). Kaplan-Meier curves for overall survival of patients with PS of 2 and 3/4 treated with nivolumab and overall survival of patients in palliative care (B). Abbreviations: OS: overall survival; PS: performance status; PC: palliative care; Cl: confidence interval.

Table 2. Therapeutic response in patients treated with nivolumab, disaggregated by PS (0/1 vs. $2-4)$.

\begin{tabular}{lcll}
\hline Response & PS $0 / 1(\mathrm{~N}=43)$ & PS 2-4 $(\mathrm{N}=20)$ & $\mathrm{p}$ value \\
\hline $\begin{array}{l}\text { No. (\%) of patients by best overall } \\
\text { response }\end{array}$ & $2(5)$ & 0 & \\
$\begin{array}{l}\text { Complete response } \\
\text { Partial response }\end{array}$ & $8(18)$ & 0 & \\
Stable disease & $21(49)$ & $3(15)$ & \\
Progressive disease & $12(28)$ & $13(85)$ & \\
$\begin{array}{l}\text { Overall response } \\
\text { No. } \% \text { of patients }\end{array}$ & $10(23)$ & 0 & $<0.001$ \\
$95 \% \mathrm{CI}$ & 11 to 36 & 0 to 23 & \\
$\begin{array}{l}\text { Disease control rate } \\
\text { No. }(\%) \text { of patients }\end{array}$ & $31(72)$ & $3(15)$ & $<0.001$ \\
$95 \% \mathrm{CI}$ & 59 to 85 & 0 to 31 & \\
\hline
\end{tabular}

Abbreviations: PS: performance status; CI: confidence interval.
A.

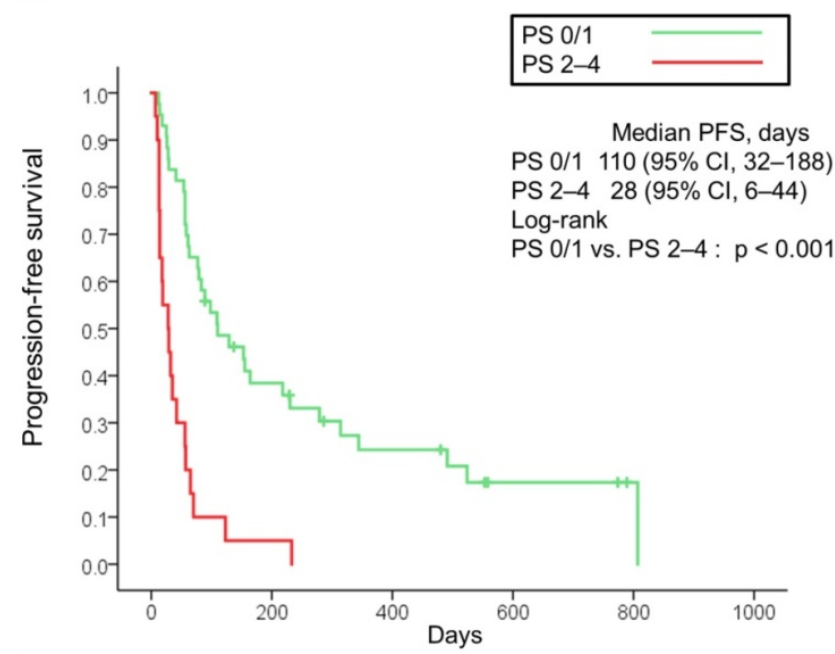

B.

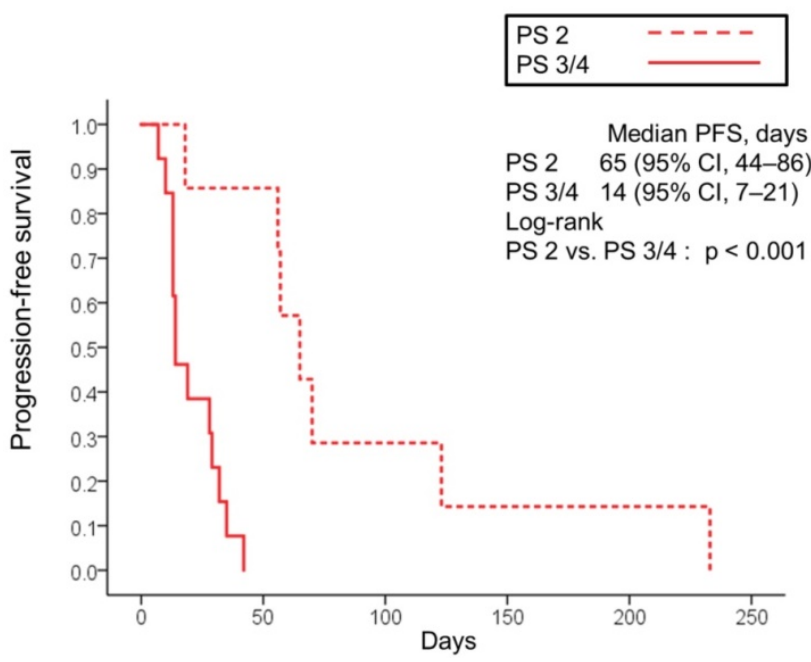

Figure 2. Kaplan-Meier curves for progression-free survival of patients with PS of $0 / 1$ and 2 to 4 treated with nivolumab (A). Kaplan-Meier curves for progression-free survival of patients with PS of 2 and $3 / 4$ treated with nivolumab (B). Abbreviations: PFS: progression free survival; PS: performance status; $\mathrm{Cl}$ : confidence interval.

\section{Safety}

Nivolumab-related adverse events observed in 2 or more patients are shown in Table 3 . The incidence of any adverse events was similar between the poor PS and the good PS groups (75\% vs. $63 \% ; \mathrm{P}=0.339)$. However, the incidence of pneumonitis in the poor PS group was significantly higher than that in the good PS group (35\% vs. $9 \% ; \mathrm{P}=0.028)$. In particular, 5 patients $(25 \%)$ in the poor PS group developed severe pneumonitis (2 patients with grade 3, 2 patients with grade 4 , and 1 patient with grade 5); the incidence of severe pneumonitis was significantly higher than that in the good PS group ( $25 \%$ vs. $2 \%, \mathrm{P}=0.010)$. Out of the 5 patients with severe pneumonitis in the poor PS group, 1 patient $(5 \%)$ died due to pneumonitis (grade 5), whereas no treatment-related death was observed in the good PS group. The proportion of patients with recent history (within one year) of thoracic 
radiotherapy (TRT) in the poor PS group was higher than that in the good PS group ( $30 \%$ vs. $9 \%, \mathrm{P}=0.054)$. However, there was no significant difference in the incidence of pneumonitis between patients with history of TRT and patients without history of TRT in the poor PS group (33\% vs. $36 \%, \mathrm{P}=1.000)$ (Table 4 ). In addition, the incidence of fever in the poor PS group was significantly higher than that in the good PS group ( $35 \%$ vs. $2 \%, P=0.001)$. In contrast, the incidence of rash in the good PS group was significantly higher than that in the poor PS group ( $19 \%$ vs. $0 \%, \mathrm{P}=0.047)$.

Table 3. Treatment-related adverse events reported in at least 2 patients.

\begin{tabular}{|c|c|c|c|c|c|c|}
\hline \multirow[t]{2}{*}{ Event } & \multicolumn{2}{|c|}{ PS 2-4 $(n=20)$} & \multicolumn{2}{|c|}{ PS $0 / 1(n=43)$} & \multirow{2}{*}{$\begin{array}{l}\text { Any } \\
\text { Grade } \\
p\end{array}$} & \multirow{2}{*}{$\begin{array}{l}\text { Grade } \\
\geq 3 \\
p\end{array}$} \\
\hline & $\begin{array}{l}\text { Any } \\
\text { Grade }\end{array}$ & $\begin{array}{l}\text { Grade } \\
\geq 3\end{array}$ & $\begin{array}{l}\text { Any } \\
\text { Grade }\end{array}$ & $\begin{array}{l}\text { Grade } \\
\geq 3\end{array}$ & & \\
\hline Any event & $15(75)$ & $6(30)$ & $27(63)$ & $6(14)$ & NS & NS \\
\hline Pneumonitis & $7(35)$ & $5(25)$ & $4(9)$ & $1(2)$ & 0.028 & 0.010 \\
\hline Fever & $7(35)$ & 0 & $1(2)$ & 0 & 0.001 & NS \\
\hline AST/ALT elevation & $4(20)$ & $2(10)$ & $4(9)$ & 0 & NS & 0.097 \\
\hline Diarrhea & $2(10)$ & 0 & $2(5)$ & 0 & NS & NS \\
\hline Anorexia & $2(10)$ & 0 & $1(2)$ & 0 & NS & NS \\
\hline Mucositis oral & $1(5)$ & 0 & $4(9)$ & $1(2)$ & NS & NS \\
\hline Creatinine increased & $1(5)$ & $1(5)$ & $2(5)$ & 0 & NS & NS \\
\hline Rash & 0 & 0 & $8(19)$ & $1(2)$ & 0.047 & NS \\
\hline Fatigue & 0 & 0 & $6(14)$ & 0 & NS & NS \\
\hline Pruritus & 0 & 0 & $6(14)$ & 0 & NS & NS \\
\hline Rash acneiform & 0 & 0 & $3(7)$ & 0 & NS & NS \\
\hline Lung infection & 0 & 0 & $2(5)$ & $1(2)$ & NS & NS \\
\hline Hot flashes & 0 & 0 & $2(5)$ & 0 & NS & NS \\
\hline Peripheral motor neuropathy & 0 & 0 & $2(5)$ & 0 & NS & NS \\
\hline ALP elevation & 0 & 0 & $2(5)$ & 0 & NS & NS \\
\hline
\end{tabular}

Abbreviations: PS: performance status; NS: not significant; AST: aspartate aminotransferase; ALT: alanine aminotransferase; ALP: alkaline phosphatase.

Table 4. Correlation between pneumonitis incidence and a history of thoracic radiotherapy.

\begin{tabular}{|c|c|c|c|c|c|c|}
\hline & PS $0 / 1$ & $N=43)$ & & PS 2-4 & $\mathrm{V}=20)$ & \\
\hline & History & f TRT wi & thin one & & & \\
\hline & $\begin{array}{l}\text { Yes }(\mathrm{N} \\
=4)\end{array}$ & $\begin{array}{l}\text { No }(\mathrm{N}= \\
39)\end{array}$ & $p$ value & $\begin{array}{l}\text { Yes (N } \\
=6)\end{array}$ & $\begin{array}{l}\text { No }(\mathrm{N}= \\
14)\end{array}$ & $p$ value \\
\hline No. & & & & & & \\
\hline Pne & & & & & & \\
\hline Yes & $0(0)$ & $4(10)$ & $<0.001$ & $2(33)$ & $5(36)$ & 1.000 \\
\hline No & $4(100)$ & $35(90)$ & & $4(67)$ & $9(64)$ & \\
\hline
\end{tabular}

Abbreviations: TRT, thoracic radiotherapy; PS, Performance status.

\section{Discussion}

In this study, patients with NSCLC with poor PS, especially 3 or 4 , who received nivolumab plus BSC showed only limited survival benefit and experienced higher frequency and severity of treatment-related adverse events as compared to patients who received BSC alone. In our study, overall survival in the poor PS group was not significantly longer than that in the PC group (median overall survival: 32 vs. 31 days). Regarding the baseline characteristics, the proportion of patients who never smoked ( $5 \% \mathrm{vs.} 50 \%$ ) and those with PS of 4 (5\% vs.44\%) in the poor PS group was lower than that in the PC group. Subgroup analyses of data from CheckMate 017 and 057 trials showed never-smoker status as a predictive factor of bad outcome in patients with advanced NSCLC who received nivolumab [2]. In addition, PS 4 was reported to be a bad prognostic factor in patients with advanced NSCLC [15]. Nevertheless, in this study, overall survival in the poor PS group was not apparently longer than that in the PC group. In a retrospective cohort study, PS $\geq 3$ was significantly associated with poor progression-free survival in patients with advanced NSCLC who received nivolumab [11]. Furthermore, Fujimoto et al. reported that progression-free survival of patients with PS of 2 who received nivolumab was significantly longer than that of patients with PS of 3 or 4 [12]. Similarly, in our study, overall survival and progression-free survival of patients with PS of 2 were significantly longer than that in patients with PS of 3 or 4 . Furthermore, overall survival in patients with PS of 3 or 4 was not significantly longer than those in the PC group. Therefore, our results suggest that BSC alone should be recommended to patients with PS of 3 or 4 . However, perhaps patients with poor PS did not benefit from nivolumab because they only received 1 or 2 cycles. Patients with better PS might live longer to gain sufficient exposure to nivolumab and have an opportunity to respond. In a study by Haratani et al. immune-related adverse events were associated with increased progression-free survival and overall survival of patients with advanced or recurrent NSCLC who received nivolumab treatment [16]. Conversely, Borghaei et al. reported that severe adverse events, including pneumonitis, were associated with decreased overall survival of elderly patients with advanced NSCLC who received nivolumab treatment [17]. In this study, regardless of severe pneumonitis, the median overall survival in the poor PS group was comparable to that in the PC group. Therefore, we also believe that severe pneumonitis is likely to shorten survival time in the patients in the poor PS group. However, diagnosed pneumonitis based on imaging test alone; therefore, progression of lung cancer could have been misinterpreted as pneumonitis.

Several predictive biomarkers of clinical response to nivolumab have been reported. These include PD-L1 expression [18, 19], neutrophil-to-lymphocyte ratio [5], C-reactive protein-to-albumin ratio [7], C-reactive protein levels [8], carcinoembryonic antigen levels [10], lactate dehydrogenase levels [11], and advanced lung cancer inflammation index [20]. In a recent study, patients with NSCLC who received nivolumab with 
pretreatment neutrophil-to-lymphocyte ratio $<5$ showed significantly longer overall survival and progression-free survival as compared to those with pretreatment neutrophil-to-lymphocyte ratio $\geq 5$ [21]. However, none of these biomarkers alone are definitive predictive biomarkers for the use of nivolumab. In our results, only 2 patients in the PS of 3 or 4 who had survival over 100 days (112 days and 114 days, respectively) had both pretreatment neutrophil-to-lymphocyte ratio $<5$ and C-reactive protein-to-albumin ratio $<1$ (date not shown). Therefore, we believe that a combination of these biomarkers may serve as an indicator for nivolumab treatment in patients with NSCLC having poor PS.

There are several limitations in this study. First, our study was retrospective in nature and included a small sample size, which limited the statistical power of the analyses. Second, data pertaining to PD-L1 expression was not available for most patients. Therefore, the survival benefit of nivolumab in patients with poor PS patients with high expression of PD-L1 could not be assessed. Third, the treatment timing and choice of regimens prior to nivolumab therapy were based on the discretion of the attending doctors, and therefore, not standardized among the patients.

\section{Conclusions}

Patients with NSCLC with poor PS, especially 3 or 4 , showed no benefit from nivolumab treatment. Further studies with larger numbers of patients are required to confirm our results.

\section{Abbreviations}

BSC: best supportive care; CI: confidence interval; HR: Hazard ratios; NSCLC: non-small-cell lung cancer; PCU: palliative care unit; PD-1: programmed cell death protein 1; PD-L1: programmed death-ligand 1; PS: performance status; RECIST: Response Evaluation Criteria in Solid Tumors; TRT: thoracic radiotherapy.

\section{Acknowledgements}

We would like to thank maruzen (http://kw.maruzen.co.jp/kousei-honyaku/) for English language editing.

\section{Ethics Committee Approval}

This study was approved by the institutional review boards of the Komatsu Municipal Hospital and the National Hospital Organization Kanazawa Medical Center.

\section{Competing Interests}

The authors have declared that no competing interest exists.

\section{References}

1. Siegel RL, Miller KD, Jemal A. Cancer statistics, 2019. CA Cancer J Clin. 2019; 69: 7-34

2. Borghaei H, Paz-Ares L, Horn L, Spigel DR, Steins M, Ready NE, et al. Nivolumab versus Docetaxel in Advanced Nonsquamous Non-Small-Cell Lung Cancer. N Engl J Med. 2015; 373: 1627-39.

3. Brahmer J, Reckamp KL, Baas P, Crino L, Eberhardt WE, Poddubskaya E, et al. Nivolumab versus Docetaxel in Advanced Squamous-Cell Non-Small-Cell Lung Cancer. N Engl J Med. 2015; 373: 123-35.

4. Vokes EE, Ready N, Felip E, Horn L, Burgio MA, Antonia SJ, et al. Nivolumab versus docetaxel in previously treated advanced non-small-cell lung cancer (CheckMate 017 and CheckMate 057): 3-year update and outcomes in patients with liver metastases. Ann Oncol. 2018; 29: 959-65.

5. Bagley SJ, Kothari S, Aggarwal C, Bauml JM, Alley EW, Evans TL, et al. Pretreatment neutrophil-to-lymphocyte ratio as a marker of outcomes in nivolumab-treated patients with advanced non-small-cell lung cancer. Lung Cancer. 2017; 106: 1-7.

6. Garde-Noguera J, Martin-Martorell P, De Julian M, Perez-Altozano J Salvador-Coloma C, Garcia-Sanchez J, et al. Predictive and prognostic clinical and pathological factors of nivolumab efficacy in non-small-cell lung cancer patients. Clin Transl Oncol. 2018; 20: 1072-9.

7. Inoue $\mathrm{T}$, Tamiya $\mathrm{M}$, Tamiya $\mathrm{A}$, Nakahama $\mathrm{K}$, Taniguchi $\mathrm{Y}$, Shiroyama $\mathrm{T}$, et al. Analysis of Early Death in Japanese Patients With Advanced Non-small-cell Lung Cancer Treated With Nivolumab. Clin Lung Cancer. 2018; 19: e171-e6.

8. Oya $\mathrm{Y}$, Yoshida T, Kuroda $\mathrm{H}$, Mikubo M, Kondo C, Shimizu J, et al Predictive clinical parameters for the response of nivolumab in pretreated advanced non-small-cell lung cancer. Oncotarget. 2017; 8: 103117-28

9. Dudnik E, Moskovitz M, Daher S, Shamai S, Hanovich E, Grubstein A, et al. Effectiveness and safety of nivolumab in advanced non-small cell lung cancer: The real-life data. Lung Cancer. 2018; 126: 217-23

10. Kataoka Y, Hirano K, Narabayashi T, Hara S, Fujimoto D, Tanaka T, et al. Carcinoembryonic Antigen as a Predictive Biomarker of Response to Nivolumab in Non-small Cell Lung Cancer. Anticancer Res. 2018; 38: 559-63.

11. Taniguchi $Y$, Tamiya A, Isa SI, Nakahama K, Okishio K, Shiroyama T, et al. Predictive Factors for Poor Progression-free Survival in Patients with Non-small Cell Lung Cancer Treated with Nivolumab. Anticancer Res. 2017; 37: 5857-62.

12. Fujimoto D, Yoshioka H, Kataoka Y, Morimoto T, Kim YH, Tomii K, et al. Efficacy and safety of nivolumab in previously treated patients with non-small cell lung cancer: A multicenter retrospective cohort study. Lung Cancer. 2018; 119: $14-20$

13. Felip E, Van Meerbeeck J, Wolf J, Ardizzoni A, Li A, Srinivasan S, et al. 193TiP. CheckMate 171: A multicenter phase 2 trial of nivolumab (nivo) in patients (pts) with stage IIIB/IV squamous cell (SQ) NSCLC who have received $\geq 1$ prior systemic treatment. J Thorac Oncol. 2016; 11: S141.

14. Ettinger DS, Wood DE, Aisner DL, Akerley W, Bauman J Chirieac LR, et al Non-Small Cell Lung Cancer, Version 5.2017, NCCN Clinical Practice Guidelines in Oncology. J Natl Compr Canc Netw. 2017; 15: 504-35.

15. Cuyun Carter G, Barrett AM, Kaye JA, Liepa AM, Winfree KB, John WJ. A comprehensive review of nongenetic prognostic and predictive factors influencing the heterogeneity of outcomes in advanced non-small-cell lung cancer. Cancer Manag Res. 2014; 6: 437-49.

16. Haratani $K$, Hayashi $H$, Chiba $Y$, Kudo $K$, Yonesaka $K$, Kato $R$, et al. Association of Immune-Related Adverse Events With Nivolumab Efficacy in Non-Small-Cell Lung Cancer. JAMA Oncol. 2018; 4: 374-8.

17. Borghaei H, Yim YM, Guerin A, Pivneva I, Shi S, Gandhi M, et al. Severe adverse events impact overall survival and costs in elderly patients with advanced non-small cell lung cancer on second-line therapy. Lung Cancer. 2018; 119: 112-9.

18. Sacher AG, Gandhi L. Biomarkers for the Clinical Use of PD-1/PD-L1 Inhibitors in Non-Small-Cell Lung Cancer: A Review. JAMA Oncol. 2016; 2: 1217-22.

19. Gibney GT, Weiner LM, Atkins MB. Predictive biomarkers for checkpoint inhibitor-based immunotherapy. Lancet Oncol. 2016; 17: e542-e51.

20. Shiroyama T, Suzuki H, Tamiya M, Tamiya A, Tanaka A, Okamoto N, et al. Pretreatment advanced lung cancer inflammation index (ALI) for predicting early progression in nivolumab-treated patients with advanced non-small cell lung cancer. Cancer Med. 2018; 7: 13-20.

21. Fukui T, Okuma Y, Nakahara Y, Otani S, Igawa S, Katagiri M, et al. Activity of Nivolumab and Utility of Neutrophil-to-Lymphocyte Ratio as a Predictive Biomarker for Advanced Non-Small-Cell Lung Cancer: A Prospective Observational Study. Clin Lung Cancer. 2018. 